\title{
ACRL Conference Highlights
}

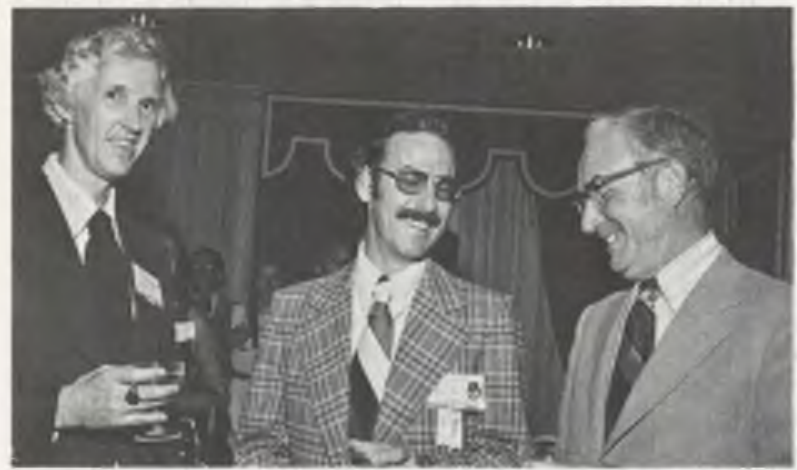

Richard M. Dougherty (center) was honored at a reception hosted by the officers of ACRL upon the occasion of his retirement as editor of C\&RL. Pictured with Dougherty are ACRL president Norman E. Tanis (left) and former C\&RL editor David Kaser (right).

NYU's Elmer Holmes Bobst Library (right and below) was the stunning setting of a Gala Open House for all ACRL members attending the New York Conference. The social highlight of the conference week, the elegant reception drew over two thousand guests.
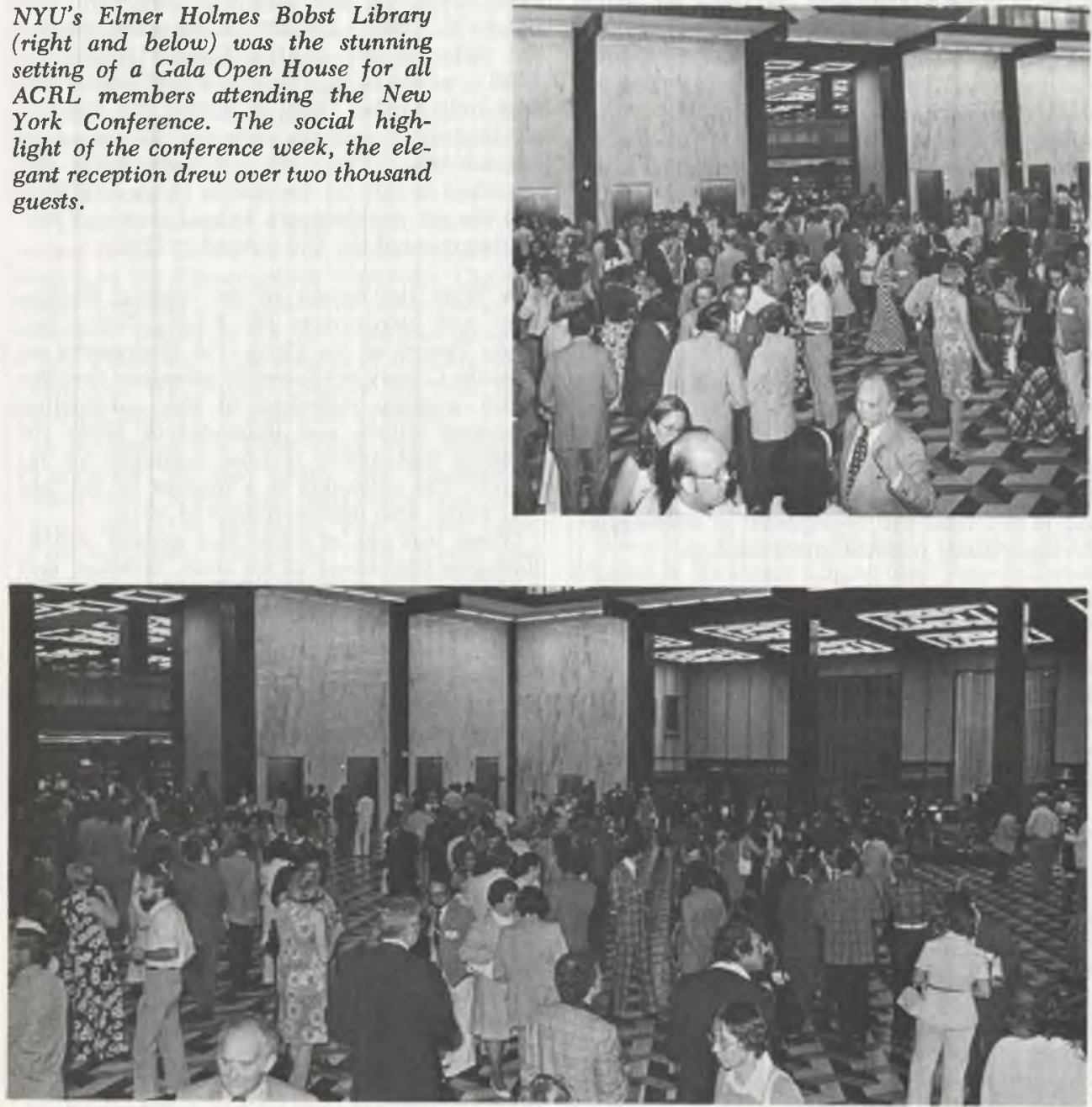